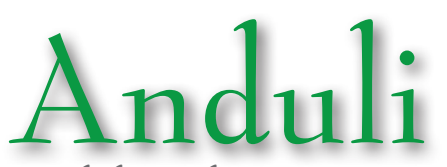

Revista Andaluza de Ciencias Sociales

ISSN: 1696-0270 • e-ISSN: 2340-4973

\title{
LOS CURANDEROS ANDINOS DE LA PEQUEÑA BOLIVIA, LINIERS, BUENOS AIRES
}

\section{THE ANDEAN HEALERS OF LITTLE BOLIVIA, BARRIO LINIERS, BUENOS AIRES, ARGENTINA}

\author{
Luis-Alberto Cárdenas \\ Universidad de Buenos Aires, Argentina \\ lacardenas9@gmail.com \\ https:/orcid.org/0000-0001-8419-2123
}

\begin{abstract}
Resumen
El presente artículo aborda las características y manifestaciones (creencias y prácticas de sanación) de los curanderos andinos en la Pequeña Bolivia, enclave étnico situado en Liniers, Ciudad Autónoma de Buenos Aires. Allí se observa un campo religioso con diversas ofertas conformando un mercado de bienes simbólicos de sanación, y en él los límites entre lo legal e ilegal, lo legítimo y lo reglamentado, se recomponen a cada momento. Esta investigación cualitativa descriptivo-exploratoria, fue realizada entre 2013-2016 mediante entrevistas en profundidad a los curanderos; pretende contribuir a una mejor comprensión de este fenómeno social que relaciona los ámbitos de la etnomedicina y la sociología de la religión. Las conclusiones hallan que los curanderos andinos representan un nuevo curanderismo urbano que cumple un rol sanador para las personas que sufren la pobreza, el desarraigo y la exclusión social.
\end{abstract}

Palabras clave: pensamiento mágicoreligioso; bienes simbólicos; sanación; salud integral; etnomedicina; cuentapropismo religioso; eficacia terapéutica.

\begin{abstract}
This article addresses the characteristics and manifestations (beliefs and healing practices) of the Andean healers in Little Bolivia, an ethnic enclave located in Barrio Liniers of the Autonomous City of Buenos Aires. There one observes a field of religious practice in which various offerings forma market for symbolic healing goods within which the limits between legal and illegal, legitimate and regulated, are continuously shifting. This descriptive-exploratory qualitative research was done between 2013 and 2016 by means of in-depth interviews with healers. It aims to contribute to a better understanding of this social phenomenon that relates the fields of ethno medicine and sociology of religion to one another. The conclusions are that the Andean healers provide a new urban folk medicine that plays a healing role for people suffering from poverty, displacement and social exclusion.
\end{abstract}

Keywords: magic-religious thinking; symbolic goods; healing; integral health; ethnomedicine; therapeutic efficacy 


\section{Introducción}

En este capítulo se aborda el estado de la cuestión que tiene dos ejes temáticos en relación con el curanderismo andino: la salud integral y las creencias religiosas.

\subsection{Salud integral y curanderismo}

En la actualidad, el debate en el campo de la salud se centraliza en la inclusión de las medicinas alternativas o complementarias (MAC) y se avanza sobre las estrategias de complementariedad con la medicina tradicional.

La Organización Mundial de la Salud (OMS) definió la medicina tradicional del siguiente modo:

...es todo el conjunto de conocimientos, aptitudes y prácticas basadas sobre teorías, creencias y experiencias indígenas de las diferentes culturas, sean o no explicables, usados para el mantenimiento de la salud, así como para la prevención, el diagnóstico, la mejora o el tratamiento de las enfermedades físicas o mentales (OMS, 2002).

La (OMS) (2013) ha desarrollado una estrategia que contempla la integración gradual de la medicina tradicional en los sistemas de salud de los estados miembros durante el período 2014-2023, centrada en la necesidad de proporcionar una mejor cobertura sanitaria universal a nivel mundial.

En cuanto a la definición de curandero, la Organización Mundial de la Salud (OMS, 2002) definió al agente de salud de la medicina tradicional. Aparece así el curandero identificado como:

Toda persona reconocida por la propia comunidad en que vive como competente para prestar atención de salud mediante el empleo de productos vegetales, animales y minerales y aplicación de otros métodos de origen social, cultural y religioso, basados sobre los conocimientos, actitudes y creencias de la comunidad en lo que respecta al bienestar físico, mental y social, y al origen de la enfermedad y la invalidez (OMS, 2002).

En la Pequeña Bolivia la publicidad callejera destaca al yatiri (curandero aymara).

El yatiri es "el que sabe", que conoce la medicina natural, es el mediador con las entidades espirituales, la naturaleza y la comunidad de pertenencia. Por lo general vive en lugares alejados, y a veces se desplaza por las poblaciones rurales, con su medicina ancestral; los pobladores le brindan alojamiento y alimentación como considera Huanca (1990). Polia Meconi (1996) hace referencias similares respecto a los médicos del Ande del Perú y Fernández Juárez (1998) lo propio con los especialistas del Altiplano boliviano.

En la ciudad de Buenos Aires eexisten dos focos de necesidades básicas insatisfechas (NBI) que presionan sobre los inmigrantes andinos en lo socioeconómico: la falta de empleo, y en lo sanitario los problemas de atención de la salud.

En cuanto a la atención en salud, Good (1987) denominó sistema etnomédico a las posibilidades que tienen las personas para la elección y combinación de medicinas populares, tradicionales y biomédicas.

Por su parte Idoyaga Molina denomina configuración etnomédica al modelo utilizado por la población urbana combinado con ofertas de la biomedicina, las medicinas alternativas, las tradicionales y las religiosas y, por supuesto, recurre al autotratamiento (Idoyaga Molina, 2002, p. 25). 
Para Goldberg (2009) este sistema es utilizado por la colectividad boliviana en Buenos Aires (Goldberg, 2009).

Ante las presiones mencionadas aparecen alternativas en el campo de las creencias religiosas en relación con la salud integral.

\subsection{Creencias religiosas y curanderismo}

En el aspecto religioso, de acuerdo con Berger (2006) y Bourdieu (1989) se reconoce un mercado de bienes simbólicos de salvación/sanación, de aquí en adelante se hace referencia al concepto de "sanación" como integrador de la salud físicoespiritual, y de modo similar se puede considerar como salud integral ya que une los aspectos mencionados tiene una dinámica atravesada por la competencia en el campo social religioso de grupos y especialistas. Por ello los especialistas en la ciudad incluyen nuevos conocimientos para atraer a un público consumidor de bienes simbólicos de sanación. Por tanto se considera que se trata de un mismo campo de sanación y salvación, de la salud y las creencias socioreligiosas que lo atraviesan.

El fenómeno religioso de "cuentapropismo religioso" o "religión a la carta" ha sido referido por Forni et.al. (2004) en la ciudad de Buenos Aires donde hombres y mujeres participan en más de un grupo o movimiento religioso, observándose el crecimiento de la oferta de sanadores carismáticos, pastores evangelistas, pentecostales y curanderos indígenas.

\subsection{La cosmovisión andina}

La cosmovisión andina es una forma de ver el mundo, cómo interpretamos la vida, cómo entendemos el universo, ¿cuáles son nuestros parámetros? (Zenteno Brun, 2009, p.4).

Esta cosmovisión no se halla cristalizada sino que se va transformando particularmente en una megalópolis como la ciudad de Buenos Aires, donde se presenta otro contexto cultural que influye en los habitantes que moran en ella.

A continuación se abordan los aspectos referentes al sistema de creencias religiosas y el concepto social de salud /enfermedad.

\subsection{Las creencias religiosas}

En las sociedades andinas la religión ocupa un lugar importante en la vida cotidiana de las comunidades, se halla en las representaciones sociales a través de las creencias y prácticas religiosas.

Para Durkheim los fenómenos religiosos contienen dos categorías: las creencias y los ritos. Las creencias consisten en representaciones y los ritos son formas de acción determinadas (Durkheim, 1968, p.40).

En la cosmología andina Viracocha es el dios creador, padre de los otros dioses, como el Inti (el sol), la Quilla (la luna), Illapa (el trueno), la Pachamama (la madre tierra), el mar, las estrellas, el arco iris. Según la creencia andina todos los elementos tienen alma, sean vegetales, minerales, animales; emiten fluidos y energías sobre el entorno y las personas del lugar.

En la cosmovisión aymara el universo se compone de tres mundos: Alax Pacha (mundo de arriba), Aka Pacha (mundo de aquí, terrenal) y Manqha Pacha (mundo de abajo, de la oscuridad) junto con una jerarquía espiritual en los tres planos mencionados. 
Como ejemplo, en las minas de Bolivia los mineros rinden culto a las entidades del lugar, sostienen la creencia que en las minas moran los demonios de la mina, comandados por el "Tío" (diablo) por lo cual para aplacarlos le ofrecen rituales y sacrificios requeridos ante el temor de sufrir accidentes y que se apropien de las almas de los hombres (Absi, 2005, p.155).

La religiosidad andina tiene como eje los espíritus de los cerros o Apus. Los Apus (apu: señor) representan los espíritus de las montañas y cerros, que cuidan los lugares, por lo cual las comunidades les rinden tributo para obtener protección en el quehacer cotidiano (Tomoeda, 1992, p. 188).

Para algunos rituales utilizan hierbas y en otros sacrifican animales con el propósito de lograr la armonización con el entorno del lugar.

Los curanderos realizan rituales para dialogar con los Apus y controlar estas fuerzas energéticas, dirigirlas y conseguir resultados. Para ello recurren a los cuatro elementos: agua, fuego, aire y tierra.

La creencia religiosa andina contiene elementos que provienen del Incanato y de la religión católica por la influencia de la evangelización durante la conquista española, obteniendo un sincretismo particular que la caracteriza.

\subsection{El concepto social de salud y enfermedad}

La medicina tradicional andina tiene una visión holística, en conjunto con el pensamiento animista del mundo.

La cosmovisión andina sobre la salud consiste en el estar bien: consigo mismo, con los demás, con los encantos y con Dios (Polia Meconi, 1996, p.98). Por lo cual el hombre andino debe mantener un equilibrio en los aspectos físico, natural, social y sobrenatural.

Para la población aymara la salud consiste en estar sano ( $\left.k^{\prime} u m a r a\right)$ físicamente para el trabajo (Mamani, 2013, p.4).

El concepto de salud andino integra dos elementos claves: la condición individual y la condición colectiva. Por un lado lo físico-psicológico de estar bien consigo mismo y por otra parte la relación armónica con la comunidad que se expresa en el "Buen Vivir", un ideario andino impulsado por el gobierno boliviano.

\subsection{El tratamiento curanderil}

El proceso de sanación empleado por los curanderos comprende el diagnóstico, la terapéutica y el resultado (eficacia terapéutica/simbólica).

El curandero debe realizar un diagnóstico para determinar el tratamiento que necesita el consultante sea físico, mental o espiritual.

Para ello realiza la lectura de distintos elementos: 'el "rastreo" con el cuy, por medio del "rastreo" con los naipes' como afirma (Polia Meconi, 1996, p.473).

Luego que el curandero ha detectado por intermedio de las diferentes formas de videncia la etiología de la enfermedad del consultante, el paso siguiente consiste en realizar la terapia adecuada para devolverle la salud perdida.

En la medicina tradicional andina se observa la influencia de la terapia humoral. La terapia humoral califica los males y remedios en cálidos y fríos como lo ha notado el médico y antropólogo Foster (1994) en relación con poblaciones de Mesoamérica, e Idoyaga Molina (1999 y 1999/2000) en relación a Argentina. 
En cuanto a la etiología de las enfermedades, estas son generadas por distintas causas. Idoyaga Molina reconoce los siguientes desequilibrios:

...Orgánicos, emocionales, sociales, espacio-ambientales, y religioso-rituales. En lo que hace al reconocimiento, diagnóstico y tratamiento de taxa vernáculos: mal de ojo, mal aire, pasmo, susto, empacho, tiricia, culebrilla, pulso, pata de cabra, brujería o mal hecho, abertura de carnes (Idoyaga Molina, 2002, p.68).

El tratamiento terapéutico que realiza el curandero por lo general comprende varios aspectos: el corporal, el espiritual, el social y el mítico.

Los soplos, baños, riegos y tomas son prácticas que los curanderos implementan para la sanación de los clientes (Guevara Corral, 1988, p. 214).

El curandero utiliza hierbas, ungüentos, emplastos, sangrías, masajes, manteos, soplos, lavajes, exudaciones, para aplicar sobre lo corporal del paciente. En cuanto a la parte espiritual en algunos casos realiza un ritual llamado misa (celebración religiosa) fundamentado en la dimensión mítica. Es decir interviene en dos aspectos físico y espiritual.

\subsection{La eficacia terapéutica/simbólica}

Este apartado focaliza la eficacia terapéutico-simbólica de los curanderos. Dicha eficacia consiste en el resultado de las prácticas de sanación implementadas por los curanderos en el tratamiento con los clientes.

Respecto a la funcionalidad del médico tradicional en el Ande peruano:

"tiene varias especialidades o funciones, además de ser conocedor de hierbas medicinales es, médico, psicoterapeuta y sacerdote del mundo mítico ancestral" (Polia Meconi, 1996, p. 93).

El curandero tiene una polifuncionalidad que interviene sobre distintos niveles del enfermo tal como se ha mencionado anteriormente.

El resultado de la terapia curanderil "está basado sobre la carga positiva del curandero, de hondo contenido psicológico, que pone a favor su fe y confianza en la restitución de la salud" (Bianchetti, 2012, p. 58).

El curandero recibe la orientación de los espíritus auxiliares. En su praxis ritual envía un flujo energético sanador hacia el paciente, quien a su vez reconoce el poder del especialista para la cura de ciertos malestares.

En referencia a la eficacia simbólica Levy Strauss señaló:

La enfermedad lleva consigo una perturbación tanto biológica como social y psíquica. El ritual terapéutico viene a restituir la personalidad social y a conseguir la recuperación física, por la eficacia real del chamanismo- curanderismo, implicando "la creencia del hechicero en la eficacia de sus técnicas," luego, la confianza y las exigencias de la opinión colectiva (Lévi-Strauss, 1958, p. 152).

En este proceso terapéutico intervienen el curandero, el enfermo y el grupo del entorno social.

En tanto Nebreda (1996) destacó la comparación del proceso de cura que utiliza el chamán sobre el enfermo con la abreacción implementada por el psicoanalista.

Por su parte, Bourdieu (2010) abordó la eficacia simbólica para explicar los fenómenos de las sanaciones que realizan los especialistas mediante los ritos religiosos, 
basándose sobre su carisma y en el poder de autoridad que concentra el saber específico.

De modo que el curandero posee autoridad sanadora, por tanto, es reconocido dentro de su comunidad como un mediador con lo sobrenatural, utilizando un código de símbolos socialmente aceptados con el propósito de la sanación del enfermo. Estos elementos culturales provienen de la cosmovisión andina.

A partir de la revisión teórica conceptual surgió la siguiente pregunta de investigación. ¿Cuál es el campo social de intervención de los curanderos en la Pequeña Bolivia?

Para trabajar sobre esta cuestión la investigación se ha centrado en el caso de los curanderos urbanos de la Pequeña Bolivia, que es el nombre popular que recibe el enclave boliviano situado en el barrio Liniers, de la ciudad de Buenos Aires.

En Argentina, el curanderismo ha sido descalificado por la biomedicina mediante el discurso médico hegemónico. Desde el aspecto jurídico el curanderismo se halla prohibido basándose en el Artículo 208 del Código Penal argentino, que dictamina la penalización a la persona que haga ejercicio ilegal de la medicina.

Las acciones del curanderismo se hallan enmarcadas dentro del ejercicio ilegal de la medicina: Código Penal, Libro II, Título VII: "Delitos contra la seguridad pública", capítulo IV: "Delitos contra la Salud Pública". El artículo 208 tipifica al curanderismo de esta manera:

La acción de quien, sin título ni autorización, anunciase, prescribiere, administrare o aplicare habitualmente, medicamentos, aguas, electricidad, hipnotismo, o cualquier medio destinado a tratar la enfermedad de las personas aún a título gratuito.

Respecto a los alcances y las limitaciones del presente estudio sobre el curanderismo andino no se emitirá juicio de valor sobre las creencias y prácticas de los especialistas. De acuerdo con Durkheim (1968) quién afirmó que una religión nunca es falsa, sino que cada una de las formas que asume tiene sus razones básicas, motivaciones y necesidades humanas que la sustentan.

\section{Métodos y materiales}

El trabajo de campo consistió en el reconocimiento de la zona, mapeo y relevamiento de la situación en torno a la salud (clínicas médicas, farmacias homeopáticas, herboristerías) y las creencias religiosas (santerías, templos, grupos religiosos, curanderos y adivinos).

En este recorrido se reconoció el modo en que interactúan los actores sociales mencionados.

Acerca del ámbito de investigación: "el campo es el referente empírico de la investigación, es una conjunción entre un ámbito físico, actores y actividades" (Guber, 2009, p. 84).

En cuanto a la recolección de datos se presentaron dificultades dado el recelo y la desconfianza de los curanderos para revelar conocimientos secretos a una persona ajena al entorno y por otra parte ante la amenaza de desalojo que pendía sobre la feria boliviana callejera. 
Respecto a los curanderos entrevistados, dos de ellos han sido contactados a través de un informante clave referente de la colectividad boliviana y otros tres especialistas mediante el contacto personal en los comercios y puestos callejeros. Los nombres de los entrevistados son ficticios con el objetivo de preservar la identidad de los mismos.

El criterio de selección de los curanderos ha sido considerado de acuerdo con en el sexo (tres hombres y dos mujeres), el lugar de origen (Bolivia y Perú), el estilo curanderil y el reconocimiento comunitario en la Pequeña Bolivia.

Asimismo se incluyó a Emilia (E6) militante social cuyo testimonio da cuenta de dificultades que padecen los inmigrantes bolivianos en el ámbito de salud hospitalaria.

En el trabajo de campo se han utilizado como técnicas las entrevistas abiertas y semiestructuradas. La guía de entrevista para los curanderos se ha basado en los siguientes ítems: lugar de procedencia/nacionalidad- edad- tiempo de ejercicio del oficio- iniciación/formación-especialidad (temas de tratamiento)- materiales utilizados en su trabajo- tipo de clientela (origen, edad, sexo, clase social).

Mediante el estudio descriptivo se accedió a situaciones y eventos reflejados en las experiencias de vida y el estudio exploratorio confirma que la temática ha sido poco estudiada en el contexto urbano de Buenos Aires. Por tanto se utilizó la técnica de observación participante/no participante.De este modo se observaron eventos, ceremonias y rituales relacionados con las sanaciones comprendidas holísticamente (física, mental y espiritual) en escenarios públicos en las celebraciones rituales andinas en la Pequeña Bolivia, Liniers.

La orientación del estudio se posiciona en el comprensivismo, incluyendo los aportes de las tipologías de Weber (1964) y Bourdieu (1989) sobre los líderes religiosos, sacerdotes, magos y profetas que constituyen una referencia para el análisis de los "nuevos curanderos urbanos" en el caso de los curanderos andinos en Liniers.

A continuación se presenta un cuadro tipológico de los curanderos entrevistados:

Cuadro 1. Características de los curanderos entrevistados 2013 a 2015

\begin{tabular}{|c|c|c|c|c|c|c|c|c|c|}
\hline $\begin{array}{l}\text { cu- } \\
\text { ran- } \\
\text { dero }\end{array}$ & Código & $\begin{array}{l}\text { Ori- } \\
\text { gen }\end{array}$ & Edad & $\begin{array}{l}\text { Oficio } \\
\text { Anti- } \\
\text { güedad }\end{array}$ & Perfil & Terapia & Elementos & Temas & $\begin{array}{l}\text { Entre- } \\
\text { vista }\end{array}$ \\
\hline ㄷㅇㅇ $\frac{\text { 응 }}{0}$ & E1 & $\begin{array}{l}\stackrel{\circ}{c} \\
\stackrel{\pi}{\pi} \\
: \frac{0}{0} \\
\infty\end{array}$ & 65 & $\begin{array}{c}40 \\
\text { Años }\end{array}$ & 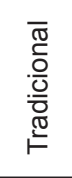 & $\begin{array}{c}\text { Videncia } \\
\text { - rituales- } \\
\text { trabajos }\end{array}$ & $\begin{array}{c}\text { naipes } \\
\text { herboris- } \\
\text { tería } \\
\text { rezos }\end{array}$ & $\begin{array}{c}\text { Pareja } \\
\text { dinero } \\
\text { salud } \\
\text { suerte } \\
\text { brujerías }\end{array}$ & $\begin{array}{c}27 / 1 / 15 \\
\text { tiempo } \\
20 \mathrm{~ms}\end{array}$ \\
\hline 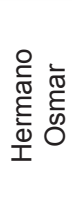 & E2 & $\begin{array}{l}\stackrel{0}{\frac{D}{0}} \\
\stackrel{0}{\frac{2}{0}} \\
0\end{array}$ & 70 & $\begin{array}{c}45 \\
\text { Años }\end{array}$ & 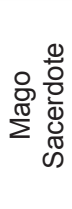 & $\begin{array}{c}\text { videncia- } \\
\text { limpias- } \\
\text { rituales- } \\
\text { trabajos }\end{array}$ & $\begin{array}{c}\text { Tarot } \\
\text { Hoja de } \\
\text { coca } \\
\text { hierbas } \\
\text { mesadas }\end{array}$ & $\begin{array}{c}\text { Pareja } \\
\text { dinero } \\
\text { salud } \\
\text { suerte } \\
\text { brujerias } \\
\text { religiosos }\end{array}$ & $\begin{array}{c}15 / 7 / 13 \\
\text { tiempo } \\
40 \mathrm{~ms}\end{array}$ \\
\hline 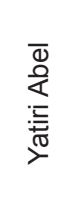 & E3 & $\begin{array}{l}\frac{0}{2} \\
\frac{0}{0} \\
\frac{2}{0} \\
0\end{array}$ & 57 & $\begin{array}{c}39 \\
\text { Años }\end{array}$ & 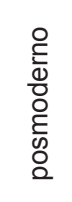 & $\begin{array}{c}\text { Videncia } \\
\text {-consejos } \\
\text { - rituales- } \\
\text { trabajos }\end{array}$ & $\begin{array}{c}\text { Tarot } \\
\text { Hoja de } \\
\text { coca } \\
\text { Amuletos } \\
\text { mesadas }\end{array}$ & $\begin{array}{c}\text { Amor } \\
\text { dinero } \\
\text { salud } \\
\text { suerte } \\
\text { brujerías } \\
\text { counselor }\end{array}$ & $\begin{array}{c}19 / 8 / 14 \\
\text { tiempo } \\
30 \mathrm{~ms}\end{array}$ \\
\hline
\end{tabular}




\begin{tabular}{|c|c|c|c|c|c|c|c|c|c|}
\hline $\begin{array}{l}\text { cu- } \\
\text { ran- } \\
\text { dero }\end{array}$ & Código & $\begin{array}{l}\text { Ori- } \\
\text { gen }\end{array}$ & Edad & $\begin{array}{l}\text { Oficio } \\
\text { Anti- } \\
\text { güedad }\end{array}$ & Perfil & Terapia & Elementos & Temas & $\begin{array}{l}\text { Entre- } \\
\text { vista }\end{array}$ \\
\hline 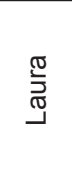 & E4 & $\begin{array}{l}\frac{\pi}{C} \\
\frac{\pi}{2} \\
\frac{2}{0} \\
0\end{array}$ & 40 & $\begin{array}{c}20 \\
\text { Años }\end{array}$ & 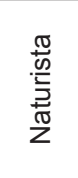 & $\begin{array}{c}\text { videncia- } \\
\text { limpias- } \\
\text { naturismo- } \\
\text { rituales- } \\
\text { trabajos }\end{array}$ & $\begin{array}{l}\text { Naipes } \\
\text { Remedios } \\
\text { mesadas }\end{array}$ & $\begin{array}{c}\text { Salud } \\
\text { Pareja } \\
\text { dinero } \\
\text { suerte } \\
\text { brujerías }\end{array}$ & $\begin{array}{r}4 / 8 / 14 \\
\text { tiempo } \\
20 \mathrm{~ms}\end{array}$ \\
\hline $\begin{array}{l}\frac{2}{\pi} \\
\frac{\pi}{\omega} \\
\omega\end{array}$ & E5 & 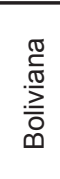 & 65 & $\begin{array}{c}40 \\
\text { Años }\end{array}$ & $\begin{array}{l}\overline{\mathbb{N}} \\
\stackrel{0}{\frac{0}{0}} \\
\frac{0}{0} \\
\frac{\sqrt{0}}{2}\end{array}$ & $\begin{array}{c}\text { videncia- } \\
\text { limpias- } \\
\text { rituales- } \\
\text { trabajos }\end{array}$ & $\begin{array}{c}\text { Hoja de } \\
\text { coca } \\
\text { Rezos } \\
\text { Hierbas } \\
\text { mesadas }\end{array}$ & $\begin{array}{c}\text { Salud } \\
\text { Pareja } \\
\text { Dinero } \\
\text { Suerte } \\
\text { brujerías }\end{array}$ & $\begin{array}{c}15 / 8 / 15 \\
\text { tiempo } \\
20 \mathrm{~ms}\end{array}$ \\
\hline
\end{tabular}

Fuente: elaboración propia

\section{Resultados}

Este capítulo se compone de la caracterización territorial de la Pequeña Bolivia y el asentamiento de la colectividad boliviana. Continuando luego con la búsqueda inmigrante de salud integral en los circuitos: etnomédico y religioso. Siguiendo con el testimonio de los curanderos entrevistados, el oficio de curandero y la oferta y demanda curanderil.

\subsection{La Pequeña Bolivia}

Desde el punto de vista urbano Liniers posee una ubicación estratégica, la avenida Rivadavia es el eje hacia el oeste suburbano, la estación homónima del ferrocarril Sarmiento, la terminal de micros de media y larga distancia, la avenida General Paz (de circunvalación) que conecta con el Aeropuerto de Ezeiza, las autopistas 25 de Mayo y Acceso Oeste y la circulación de medios de transporte hacia distintos puntos cardinales, convierten al lugar en una zona de transferencia con presencia de público permanente.

En 1984 se produjo el cierre del Mercado de Liniers, centro de abasto de frutas y verduras en la zona oeste de la ciudad de Buenos Aires y alrededores. En aquel momento un reducido grupo de la colectividad boliviana que trabajaba en dicho lugar se desplazó a la venta en las veredas cercanas al ex Mercado. Posteriormente, algunos de estos vendedores ambulantes que lograron consolidarse económicamente se instalaron en comercios de las adyacencias y luego trajeron a sus familiares asentándose en la zona. Durante la década de 1990, paulatinamente se incrementó la presencia de la comunidad boliviana en la zona cercana a la Estación Liniers.

En la Pequeña Bolivia se ubican comercios de productos regionales, restaurantes de comidas y bebidas típicas, que constituyen lugares de encuentro de la colectividad boliviana. En el llamado "microcentro boliviano" se observa una gran actividad en el área de servicios: estudios jurídicos, agencias de viaje, gestorías, correo internacional, locutorios y locales de reenvío de dinero. Asimismo, en la zona se ubica una feria boliviana ambulante con puestos y manteros, con la venta de ropa, comida, artesanías y elementos para los rituales de la cultura andina.

El carácter ilegal de la feria genera conflictos con el gobierno de la ciudad de Buenos Aires que periódicamente envía inspecciones con miras al desalojo. 


\subsection{La búsqueda inmigrante de la salud integral}

Desde la perspectiva sanitaria, en el sector sur de Liniers se ubica el hospital Santojani, que atiende un radio importante, y en particular a las colectividades boliviana y peruana.

En la zona se registra la existencia de clínicas médicas, odontológicas, ginecológicas, farmacias homeopáticas y herboristerías

Las clínicas médicas, ginecológicas y odontológicas de la zona promueven la orientación de la medicina comunitaria social y solidaria. De modo que dichas instituciones responden a necesidades de la colectividad andina.

Respecto a la cuestión sanitaria se presentan problemáticas agudas. En 2005 a través del resultado de una investigación sobre la situación de precariedad laboral y la salud de los inmigrantes, se pudo identificar a la tuberculosis como la principal enfermedad; los inmigrantes representaron el $79,48 \%$ de los atendidos por tuberculosis en el hospital Santojani de los cuales el 71,79\% eran bolivianos (Goldberg, 2009, p.237).

Emilia, militante de la colectividad boliviana, coordinadora de un grupo de mujeres relató las situaciones de discriminación que se les plantearon a los migrantes en el ámbito sanitario público:

Nos organizamos por los problemas de discriminación a nuestros hijos en las escuelas, en los hospitales, en el Santojanni, en el Piñero, en el Vélez Sarsfield, te dicen: "Tienes que hacer un estudio en tres meses, anotan debajo de la orden 'es boliviano', a mí me pasó. En Bolivia hay hospitales que dan remedios a los que necesitan, cuando no es extremo pagan. Yo creo que si en los hospitales nos cobraran, si pudieran hacer eso, nos van a atender tal vez con garantía. Otra cosa porque no van los paisanos a los hospitales, los médicos son muy acelerados, hablan fuerte, el boliviano habla bajo, no le entienden, no le quieren repetir (E6, entrevista17 de septiembre de 2013).

El relato del informante remite a los enfoques de Kleiman (1980) y Menéndez (2002) respecto a la relación médico-paciente.

El enfoque de Kleinman (1980) distingue entre disease (enfermedad) como cuadro clínico que interesa a los médicos e illness (padecimiento), en este caso la enfermedad percibida por los enfermos. De esta manera la medicina oficial se ocupa de la disease y los curanderos consideran la illness la perspectiva social, la familia y el entorno comunitario. Illness (padecimiento) es la experiencia subjetiva del paciente sobre su enfermedad, influenciado por la cultura de pertenencia y el entorno familiar-social.

Desde el enfoque de Menéndez (2002) la biomedicina desconoce/niega la importancia de la palabra del paciente con sus representaciones culturales.

En Buenos Aires, los inmigrantes bolivianos encuentran que los médicos no reconocen cierto tipo de padecimientos, comprendidos dentro del espacio de la medicina popular, por considerarlos mágico-religiosos (Goldberg, 2009, p.240).

Por una parte, se encuentra la situación de los migrantes, con sus dificultades para la documentación (algunos de ellos indocumentados). Por otra parte, por la situación crítica de la salud pública con el estado de saturación en la atención del hospital público. Como se mencionó anteriormente, un factor de importancia es la cuestión referente al trato personal y la comunicación entre médico y paciente. 
El circuito de búsqueda de salud de los inmigrantes bolivianos presenta distintas opciones:

En primer lugar, la recurrencia a la autoatención, en caso contrario la consulta a un terapeuta especialista representante de la medicina andina (aymara o quechua) o al médico de un servicio público de salud, o las clínicas privadas con personal de salud boliviano (por ejemplo, Virgen de Urkupiña en Pompeya, clínica en Liniers) o directamente regresar a su lugar de origen para ser tratados por un curandero o terapeuta representante de la medicina andina (Goldberg, 2009, p. 239).

Este circuito remite al sistema etnomédico de Good (1987) y la configuración etnomédica de (Idoyaga Molina, 2002, p. 25) más ajustable al caso de Buenos Aires.

Desde la perspectiva religiosa en Liniers se observa un campo religioso con una diversidad de ofertas conformando un mercado de bienes simbólicos de sanación. En el barrio se encuentran iglesias pertenecientes al catolicismo (especialmente el santuario de San Cayetano con una multitudinaria convocatoria y destacada actividad pastoral y social), evangélicas, pentecostales, adventistas y centros espiritas. Allí se observó el fenómeno religioso de "cuentapropismo religioso" referido por Forni et al. (2004).

Considerando el concepto de Anderson (1981) sobre el fenómeno urbano de agrupación geográfica por similitudes de actividades, la zona de Liniers se ha convertido en un mercado especializado que aglutina cultos, adivinos y curanderos.

Esta diversidad de cultos populares y manifestaciones religiosas se hallan especialmente relacionadas con la búsqueda de un mayor bienestar físico-emocional, con el intento de solucionar malestares y enfermedades que no han encontrado respuestas en otras instancias. Las ofertas religiosas aparecen compitiendo en un mercado complejo que comprende tanto a los males del cuerpo como a los llamados males del alma.

En Liniers, se observa gente que pasea de compras por el shopping (ex mercado) donde emergen los duendes del pasado, los inmigrantes europeos, los trabajadores bolivianos que llegaron después para quedarse. Allí cerca, los comercios de la Pequeña Bolivia exhiben una amplia oferta de mercaderías, despiden aromas de especias y alimentos cocidos; la música andina suena en las galerías comerciales, los televisores emiten recitales de conjuntos musicales y lucha de mujeres en el campo boliviano; una marea de gente se desplaza, se ven cholas con sus atuendos típicos y en las veredas los manteros trashumantes exponen sus mercancías como en el Mercado del Alto, La Paz (Bolivia).

En las esquinas los pentecostales y los Testigos de Jehová luchan por las almas de futuros conversos. Enfrente de ellos se ve la presencia de los yatiris, quienes con sus augurios y mediaciones dan una imagen colorida especial en una versión porteña del altiplano.

\subsection{Los curanderos de la Pequeña Bolivia}

La Pequeña Bolivia es un reconocido mercado de bienes de sanación tal como se publicita en medios periodísticos.

El diario digital Opinión publicó el artículo "Yatiris":

Una de las actividades que llama la atención en Liniers es la que se dedican Antonia y Teodora, dos mujeres que leen la suerte en la milenaria hoja de coca y la curación de personas que son "víctimas de hechizos o brujerías". Con un aguayo 
en una pequeña mesa, ambas mujeres de origen paceño, se sientan frente a frente en una de las calles de Liniers. Ofertan sus servicios de la lectura de la hoja de coca para el trabajo, la familia, salud y amor. Asimismo, preparan mesas rituales para la Pachamama y las personas que lo necesiten. Sus clientes son por lo general residentes bolivianos, pero aseguran que no faltan los argentinos que también creen en este tipo de rituales y se hacen la lectura y compran q'oa' (http://opinión. com.bo) (15/12/13).

Para la presente investigación se ha entrevistado a los curanderos Don Leopoldo, Hermano Osmar, Abel, Laura y señora Caty.

En las entrevistas se constata que predomina la procedencia de territorios andinos de Bolivia y de Perú, desde donde han emigrado por razones familiares y/o personales.

Don Leopoldo es un hombre de sesenta y cinco años, boliviano, de contextura mediana, piel cobriza, que se encuentra al frente de un puesto callejero en la calle José León Suárez, sentado ante una pequeña mesa, sobre la cual se haya extendido el tari (tejido sobre el que se efectúa la lectura orientativa de los naipes u hojas de coca), un mazo de naipes españoles, un crucifijo y una botella de alcohol; al costado tiene dos sillas pequeñas destinadas a los consultantes. Don Leopoldo relató su procedencia y el motivo del viaje a Buenos Aires:

Soy del Alto, La Paz, Bolivia, estoy hace dos semanas; yo venía constantemente desde 1990 a visitar a mis paisanos, trabajaba en la calle, y ahora también me encuentro trabajando en la calle. La feria 16 de Julio es casi parecida, mucho más grande, cualquier cosa vende, parece la feria de bolivianos de acá. Aquí a la vueltita, hay un señorcito, es paceño, Eladio, llegó después de mí, hace cinco años, yo vengo desde hace veinticinco años. En Santa Cruz, Bolivia, yo tengo un consultorio, yo me he venido, ahora está un poquito medio bajo los pesos argentinos, ya casi no conviene estar aquí. Pero yo me he venido porque tuve un problema allá, me separé de mi señora; como yo conocía siempre, por eso me he venido aquí, para olvidar a mi esposa, estaba sufriendo allá; para cambiar, me voy a quedar un tiempo, hasta que me olvide, después retornaré (E1, entrevista 27 de enero de 2015).

El yatiri Don Leopoldo destaca la similitud del ambiente de la feria de Liniers con la feria de El Alto. En el relato del entrevistado se reconoce la conexión entre el lugar de origen y el lugar de anclaje, la movilidad de territorio comprende itinerarios y enclaves.

Asimismo destaca las redes de connacionales que proporcionan la posibilidad de trabajo y albergue en los lugares de tránsito, en tanto se recupera de la separación de su pareja.

Por tanto, es importante la relevancia de los vínculos, redes e interconexiones que los emigrantes establecen y sostienen, tanto con su lugar de origen como en el sitio de destino (Solé et. al, 2008).

El Hermano Osmar es un hombre de setenta años, peruano, alto, piel cobriza, cabeIlo largo con una coleta atada. El consultorio de Osmar se encuentra en un departamento cercano a la estación Liniers. El ambiente está decorado con posters alusivos al chamanismo; en un modular se apilan cajas de DVD relativos a la temática, y en la pared se exhiben diplomas de la Asociación de Chamanes en Perú y una foto del grupo de Osmar en un estudio de televisión ataviado con vestimentas tradicionales. 
El Hermano Osmar se alegró del reencuentro (luego de diez años) en la nueva entrevista:

Mi nombre es Osmar, bautizado como chamán, gracias hermano que has venido para esta entrevista, segunda entrevista que me haces, muy contento de este regalo que me has dado (el libro "Ayahuasca") y esta música que estas escuchando, es una música especialmente para plantas, porque las plantas necesitan música, para que aviven la planta (E2 entrevista15 de julio de 2013).

Otro entrevistado es el yatiri Abel. El consultorio se halla ubicado en la calle José León Suárez; en la terraza un cartel anuncia "Yatiri Abel". Una escalera conduce a la planta alta de la vieja casa. El ayudante es un muchacho joven, con una renguera en una pierna, quien se dirige a la cocina donde prepara hierbas que desprenden un fuerte olor e invaden la casa, luego prepara unos carbones en una sartén. Una pared de la sala de espera exhibe cuadros de personalidades, tales como Túpac Amaru, José Mariátegui, Ernesto "Che" Guevara y Sigmund Freud. En el consultorio donde atiende Abel, se observa un cuadro grande de Freud, ubicado detrás del escritorio.

El yatiri Abel es un hombre de cincuenta y siete años, peruano, de talla pequeña, piel oscura, su hablar es pausado. Se presentó del siguiente modo:

Mi nombre es Abel, soy de Puno, Perú; hace años que vine a Buenos Aires y estoy en Liniers. Mi especialidad es sobre el tema de parejas, atiendo en el consultorio, soy counselor y también dicto clases sobre chamanismo y metafísica (E3, entrevista 19 de agosto de 2014).

El especialista presenta su perfil profesional alineado en la New Age, destacando su título de counselor y la enseñanza de chamanismo y metafísica.

La sanadora Laura es una mujer de cuarenta años, peruana, delgada, de piel blanca, ojos verdes. Se halla en la calle José León Suárez, al frente de un puesto de venta de productos naturales (promociona el remedio unicista Noni con extracto de vegetales andinos), remedios, pomadas, ungüentos y libros sobre medicinas herbolarias.

Laura relataba su procedencia:

Hace dieciocho años que estoy en Buenos Aires. Hace catorce años que empecé a trabajar en la feria. Yo soy del norte de Perú, del departamento provincia de Piura, cerca de Ecuador, con un clima cálido llegando a 32 grados todo el año. Es una zona donde están los mejores curanderos, la parte de la sierra de Piura, la Huaringa de Huancabamba, está a un trayecto de diez horas de camino de Piura; en la serranía es propio del lugar que se hable un poquito de quechua. Te puedo decir que cuando se menciona a la Huaringa de Huancabamba como un sitial donde van todas las personas que necesitan la sanación, encuentran ahí la sanación espiritual, la sanación de enfermedades, sanación de todo (E4, entrevista 4 de agosto de 2014).

La entrevistada proviene de una zona reconocida dado que se encuentran curanderos y chamanes sanadores, y atrae a un público de peregrinos que buscan la sanación integral.

Nizama (2015) publicó un artículo en diario La República sobre "El curanderismo, una tradición con gran arraigo en Piura. Misticismo":

Esta práctica hoy se ha extendido en todo el norte del país. Las famosas lagunas de las Huaringas, en la sierra piuriana, son muy concurridas por los visitantes. Más allá de las creencias religiosas y métodos científicos de sanación existe una 
tradición curandera muy arraigada en los corazones de los piurianos, y en general en el norte del país. Así lo demuestran los miles de personas que diariamente buscan algún curandero para conocer cuál es el motivo de su mala suerte, curar la enfermedad que los aqueja o para una "limpia" o un baño de florecimiento. Uno de los centros del curanderismo en el Perú se ubica en la provincia de Huancambamba, situada en la sierra de Piura, donde se destaca un complejo de catorce lagunas conocidas como las Huaringas, y entre ellas sobresalen la Shimbe y Negra. Hasta alli llegan aproximadamente tres mil turistas mensualmente para participar de las mesadas, aquellos rituales celebrados desde la medianoche hasta las cinco de la mañana al pie de las lagunas (Nizama, 2015) (http://larepublica.pe).

La señora Caty es una mujer de sesenta y cinco años, boliviana, de talla pequeña, delgada, de piel cobriza, ubicada en un comercio de la calle $X_{X X X X X X}$. Allí tiene dos pequeños locales, en uno de ellos guarda elementos para los rituales y en otro donde atiende a los clientes. En el fondo se encuentra un patio en cuyo centro se erige la estatua del apóstol Santiago, hacia un lateral se observan braseros y elementos que utiliza para las misas rituales y las festividades del Ekeko, entre otras.

"Soy yatiri naci en la Paz, Bolivia, vine hace mucho tiempo a Buenos Aires, atiendo en este lugar, soy seguidora del Santiago Apóstol que es el médico sanador" (E 5, entrevista 15 de agosto de 2015).

De acuerdo con los testimonios existe un continuum entre el Ande y la Pequeña Bolivia, en torno a un mercado de bienes simbólicos de sanación.

\subsection{El oficio de curandero}

En este apartado se caracteriza al curandero andino, su iniciación, tipología y rol específico.

Según se ha averiguado por las entrevistas realizadas, el oficio de curandero implica idoneidad y responsabilidad para cumplir con la función específica dentro de la comunidad de pertenencia. Una persona común no puede convertirse en curandero por iniciativa propia, una cuestión previa es el llamado o señal que lo signa para ser iniciado con el propósito de cumplir dicho rol específico.

El requisito primordial para ser yatiri, es ser señalado para cumplir con tal misión específica. Este llamado puede presentarse de distintas maneras, por un hecho fortuito, por un accidente o acontecimiento extraordinario (la caída de un rayo), por herencia familiar, o adquisición por formación con un curandero/a que le transmite sus conocimientos.

La especialización entre médicos campesinos andinos se fundamenta "en la adquisición de un poder especial que lo faculta a curar afecciones comunes o naturales, que requieren el empleo de algunas hierbas o productos orgánicos" (Bianchetti, 2014, p.153).

En cuanto a la implicancia del sanador "la iniciación es un pasaje importante en la vida del curandero, conlleva un compromiso personal integral: físico, mental y espiritual". (Gómez Briones, 1996, p.105).

El curandero en su función social: "cuida la salud, protege contra los "contagios" espirituales que causan la enfermedad, asegurando el normal desarrollo de las actividades cotidianas" (Polia Meconi, 1996, p.101).

Don Leopoldo hizo referencia a las señales para ser yatiri, y el don de sanación personal: 
Bueno, nosotros tenemos un don, nacimos con un don; o sea que esto viene, no somos herederos de nuestros abuelos, sino que uno nace con un don. Yo nací con cinco estrellas, con cinco coronas digamos (señala la coronilla). Las cinco coronas es una señal, remolinos en la cabeza. Entonces por eso manejo estas cosas. Porque así por así no más la gente no puede acertar. Los gemelos por ejemplo aciertan. Especialmente los gemelos, ellos también saben, los que son ligados con el rayo relámpago esos también igual, con seis deditos en los pies, esos son los que tienen ese don. Si, el don, yo tenía unos siete años por ahí, yo tenía un abuelo que manejaba esto también. Entonces, cuando en el campo llueve llega a granizar, esas cosas, muchas veces, eso hace mal a la chacra, todo eso, el abuelo me decía: "Tú tienes ese don, tú tienes que ser igual que yo" (E1, entrevista 27 de enero de 2015).

El Hermano Osmar comentó el legado familiar:

Mi padre me dejó la herencia, yo soy el único de mis siete hermanos; el menor de mis hermanos me está ayudando allá en el Perú, mis otros hermanos no, son profesionales, trabajan en otras cosas. Yo hace tres años y medio, me vine por una misión, yo soy un chasqui en sí, yo vengo a dar conferencias, ahora estoy dando más conferencias, quiero difundir el chamanismo y las comunidades indígenas (E2, entrevista 15 de julio de 2013).

El entrevistado se refiere a la transmisión de conocimientos de sus ancestros y su raigambre cultural en la comunidad. La misión de Osmar es ser chasqui (mensajero), por lo cual su objetivo es difundir el pensamiento indígena de manera como lo viene desarrollando en las conferencias y eventos en Sudamérica.

El yatiri Abel relató su testimonio de su iniciación en su ámbito familiar:

Yo esto lo heredo de mis abuelos, que eran yatiris; los chamanes de la comunidad. Yo aprendí de ellos, aparte de mis padres y mis abuelos; aprendí en la infancia y en la adolescencia. En mi comunidad, más que todo, mi abuelo era chamán, y entonces todos concurrían a consultar, hacer las preguntas, pedir las sanaciones. Yo le ayudaba. Cuando él se va de este mundo, entonces me conocían, yo me veía como obligado a suplantarlo, poco a poco comenzaron a buscarme, entonces yo me gané un lugar, es que uno se lo gana, no es que uno se autodenomina, se ubica en ese lugar, es la comunidad, es la consejera, en otras palabras, te vienen a preguntar, te ubican en ese lugar (E3, entrevista 19 de agosto de 2014).

La sanadora Laura reconoció la tradición curanderil en su familia:

En mi familia en sí, mi padre tiene ochenta y cinco años (viene como del pasado de parte de él que es curandero) y mi tío que ya falleció. Dentro de todo eso, la parte de sanación, en la familia de mi papá la llevan muy discretamente. Lo que hace toda la familia es la parte de las hierbas, del uso de la ayahuasca, pero con sumo cuidado (E4, entrevista 4 de agosto de 2015).

Laura refirió que este don conlleva a guardar secretos de los conocimientos propios del oficio sobre las plantas sagradas y los rituales de sanación.

La señora Caty comentó sobre el don de sanación:

Vengo de una cadena desde los tatarabuelos, ya me lo señalaron la familia desde que nací, uno no elige, no son todos, es quien tiene que ser, si es mujer o si es hombre, tiene que tener sabiduría. Se presenta en el sueño, tengo que soñar para decir, si se embaraza mi hija (E5, entrevista 15 de agosto de 2015). 
En el caso de las entrevistadas se confirma la importancia del entorno familiar curanderil y de la cadena de transmisión de conocimientos de sanación. De acuerdo con el testimonio de los entrevistados, si bien aparte de provenir de una línea familiar de reconocidos curanderos, finalmente es la comunidad quién otorga la certificación del curandero.

El curandero para acceder al estatus de médico popular tiene que atravesar una suerte de iniciación en la que adquiere poder, auxiliares y conocimientos. Por tanto, el curandero, retribuye a los encantos y espíritus auxiliares quienes le dieron el don de la videncia y lo asisten en su trabajo de terapeuta y adivino con las ofrendas y rituales de agradecimiento.

El compromiso que adquiere el nuevo yatiri no admite renuncias de ningún tipo. La persona que desatienda su compromiso como elegido del rayo está expuesta a desgracias (Fernández Juárez, 2004).

El yatiri asume el compromiso de utilizar todo su saber para el bien de la comunidad y rendir sacrificio a los espíritus tutelares, la Pachamama y los Santos, destacándose la encomendación de los yatiris a Santiago Apóstol para los rituales de sanación.

A continuación, se presenta una tipología de los curanderos sanadores entrevistados en el trabajo de campo.

Don Leopoldo (E1) se puede considerar un curandero tipo tradicional. Representa a la figura del médico de campo, tal como se reconoce a sí mismo, en su función de curandero, que recurre a las prácticas tradicionales y la herboristería para la sanación de las enfermedades y malestares de los clientes. En su oficio curanderil recorre distintos lugares de la Argentina, en los períodos que visita el país; las redes de paisanos le dan lugar de acogida para que brinde la atención necesaria.

El Hermano Osmar (E2) desempeña (en sentido weberiano) dos roles sociales: mago y sacerdote. En el primer rol con la atención de casos individuales de consulta sobre los temas clásicos de taxa vernáculos, amarres, conflictos familiares, económicos; en el segundo rol como líder de la Agrupación Los Hijos del Sol del Tawantinsuyo, con el objetivo de fundar un templo solar en Buenos Aires.

El yatiri Abel (E3) representa el nuevo curandero posmoderno con la apertura e inclusión de estudios terciarios (counselor), y alternativos como la metafísica y la parapsicología, con el propósito de satisfacer la demanda de los clientes en el dinámico mercado de Buenos Aires. Se reconoce como especialista en temas de pareja, prepara el warmi munachi y el chacha munachi, también brinda cursos de chamanismo andino.

La sanadora Laura (E4) si bien tiene formación biomédica (ha sido obstetra en Perú), su rol actual remite a la curandera naturista, ligada a la medicina humoral y por otra parte con la apertura para incorporar elementos del mercado posmoderno, por ejemplo, el remedio unicista Noni (de amplio espectro curativo) publicitado en la radio durante la madrugada. La sanadora organiza tours a las Huaringas de Huancabamba, Piura, Perú, llevando consultantes a la zona de las lagunas donde se encuentran los maestros curanderos.

La señora Caty (E5) representa la figura clásica de la mujer yatiri, con la oferta de las mesas para la Gloria Pachamama, así como también soluciona problemas de pareja, familia, salud y trabajo. Seguidora del apóstol Santiago, el Santo del Rayo de la sanación, tiene una clientela que consulta asiduamente en su local comercial y también asiste a los lugares de trabajo y viviendas para los rituales propiciatorios y de limpieza. 


\subsection{La oferta y demanda curanderil}

En Liniers circula la propaganda callejera de los curanderos andinos, con una variada oferta de soluciones.

Limpieza de casas, talleres, verdulerías, quintas y fábricas, amarre de dinero, enfermedades desconocidas, florecimiento de su vida, pacha ánimo ajayu (ritual de la Pachamama para llamar el ánimo), huesero, preparo todo tipo de mesas. Abrecaminos en tu negocio, limpieza espiritual, salud, quita maleficios, llama ánimo. Suerte en el amor, suerte en el trabajo, salud (texto del anuncio de un curandero de la Pequeña Bolivia, 2016).

Las demandas de consulta de los consumidores de bienes simbólicos de sanación se corresponden con los temas referidos al amor, salud, dinero, trabajo y daños; los curanderos ofrecen sus saberes y prácticas en estas temáticas que se describen a continuación:

Amor: en primer término, emerge el tema del amor, dado que en general los curanderos se publicitan como especialistas en temas del amor/unión de parejas:

Tu pareja se fue, estás sola y angustiado, no tienes suerte en el amor. Soluciono toda clase de problemas en el amor, amplio conocedor de magias y secretos para acabar con los sufrimientos.

Haz volver al ser amado (texto del anuncio de un curandero de la Pequeña Bolivia, 2016).

Con el diagnóstico previo puede reconocer el problema y buscar la solución:

Oriento sobre su destino amoroso mediante cartas, tarot, foto y líneas de la mano. Indígena boliviana hechicera lee coca y orienta sobre tu destino amoroso. Basta foto, prenda, $100 \%$ garantía (texto del anuncio de un curandero de la Pequeña Bolivia, 2016).

La atención comprende parejas, matrimonios, amantes y sus implicaciones vinculares tales como: atracción, rechazo, deseo, bloqueos, falta de deseo, enamoramiento, desamor, uniones, separaciones, peleas, mala suerte, dificultad de comunicación, frigidez, impotencia, entre otras situaciones sociales.

Para el tratamiento de estas problemáticas el curandero o curandera realiza los amarres del amor:

Curandero del amor hace amarres para enamorados, novios, une parejas separadas, amores imposibles, devolviéndote la felicidad. No sufras más en el amor, curandero indígena reúne a los separados haciendo un amarre de unión espiritual.

Amarres fuertes para el amor, atracción, retornos y unión de parejas (texto del anuncio de un curandero de la Pequeña Bolivia, 2016).

Para la unión de parejas, prepara pociones, perfumes, amuletos, como el warmi munachi para conseguir el amor de la mujer deseada y el chacha munachi para atraer al hombre, entre otros recursos.

Dinero: un anuncio típico, "Curo negocios, casa, talleres, oficinas", la oferta curanderil consiste en la ofrenda de mesadas a la Pachamama y rituales para el florecimiento y la prosperidad de la familia, abarcando principalmente las actividades de la colectividad en comercios, verdulerías, fábricas, talleres y quintas. 
Salud: abarca tanto las enfermedades consideradas de la experiencia del curandero (taxa vernáculos), como aquellas de desconocida etiología=síntomas u origen (males extraños de acuerdo con las creencias culturales). Entre los rituales se hallan la oferta de llamado del ánimo de la persona, las limpias para armonizar, sanar y proteger a las personas consultantes.

Daños: comprende la influencia de las brujerías, hechizos, conjuros, maleficios, generalmente provenientes del entorno social inmediato por envidias, rivalidades y competencias de diversa índole. La oferta remite a la ofrenda de mesadas negras para cortar los maleficios, hechizos y todo tipo de brujerías, así como también la confección de amuletos y talismanes personales para la protección y ayuda en lo cotidiano.

Entre las ofertas curanderiles de convocatoria masiva se destacan las celebraciones rituales andinas: el 21 de junio es el Inti Raymi, el 1 de agosto la Pachamama, el 21 de diciembre el Capa Raymi que es el último mes que le da gracias a la tierra por todos los beneficios, otra fecha de culto, es el 1 de noviembre o Aya Marca el mes de los difuntos, el 24 de enero las Alasitas (Fiesta del Ekeko, personaje mítico que simboliza la fortuna).

Los yatiris bendicen la ofrenda del cliente, hacen la aspersión con alcohol, rezan para que el Tata Inti (Dios Sol) abra los caminos, que vaya bien en la salud, la familia, el trabajo, la suerte.

Los curanderos se presentan en público con la facultad de la videncia para la revelación de personas y hechos relacionados con quien consulta, así como las posibles soluciones, estableciendo una comunicación maternal/paternal en la escucha y orientaciones. Asimismo, los especialistas en su mayoría se reconocen con dominio sobre el tiempo y el espacio y con poder de influencia sobre las problemáticas de consulta:

El gran indio yatiri conoce los secretos y misterios de los trabajos y rituales indígenas. Poder indio, fuerza indígena, todo lo puede. Nada es imposible. Soy el mejor. Trabajos infalibles.

Soluciones inmediatas (texto del anuncio de un curandero de la Pequeña Bolivia, 2016).

A la vez, ofrecen un marco de seriedad, confianza y garantía.

En el trabajo de campo en la Pequeña Bolivia se constató que los especialistas tienen una tarifa de consulta en común, a modo de código de convivencia. Después, cada curandero ajusta el cobro de acuerdo a la intervención que debe realizar surgida del diagnóstico previo.

\section{Discusión y conclusiones}

Los curanderos andinos de la Pequeña Bolivia, representan una nueva forma de curanderismo urbano. Al respecto resulta importante destacar la relevancia del vínculo entre lo religioso y la salud integral, en relación con los aspectos relevantes del sistema de creencias religiosas y los conceptos de salud y enfermedad, que son mediatizados por el curandero. 
A diferencia de los autores que ubican al curandero como agente de la medicina popular, este estudio muestra que los curanderos andinos se sitúan entre la medicina popular y la religión.

Una visión similar expuso Briones (1996) respecto de los curanderos andaluces. A diferencia de los curanderos andaluces que son de creencia católica, los curanderos andinos manifiestan una síntesis particular producto de las raíces indígenas y la influencia católica española. Además, el curandero andino en Liniers participa de oficios religiosos tal como se ha observado en el trabajo de campo, dado que en Buenos Aires se encuentra en un contexto diferente al andino, por lo cual su rol se diversifica en función de las necesidades de la comunidad y la clientela.

De esta forma se comprende el fenómeno de la presencia de curanderos y yatiris con sus implicancias, respecto a las creencias y las sanaciones en el campo religioso que confluyen en el mercado de bienes simbólicos de sanación de la comunidad de la Pequeña Bolivia.

La lógica del mercado de bienes simbólicos de sanación comprende por una parte la demanda (padeceres y malestares) de los consumidores y por otra, la oferta (saberes y prácticas) brindada por los especialistas.

Los consumidores solicitan a los especialistas consultas de atención y solución a problemas económicos, desempleo, conflictos familiares, y estrés, que son propias de la sociedad posmoderna, en particular de las grandes urbes, como en el caso de la Ciudad Autónoma de Buenos Aires.

Los curanderos de la Pequeña Bolivia ofrecen soluciones a los problemas del amor, la salud y la prosperidad. La práctica curanderil proporciona una respuesta para el inmigrante que padece la pobreza, la marginalidad y la discriminación. En los casos de soledad, la búsqueda del amor se presenta como reafirmación personal, a través de la posesión de los afectos del ser deseado.

El curandero andino es un sanador que cumple un rol social ofreciendo su servicio para las posibles soluciones ante problemas económicos, vinculares, familiares, de pareja, laborales, desgracias, males sin solución aparente, brujerías y daños.

Así también se observó una correlación entre el flujo migratorio andino y la llegada de yatiris a Liniers (registrada en la publicidad callejera) quienes con sus métodos religiosos de sanación cubren distintas necesidades de la comunidad en el ámbito urbano de Buenos Aires.

En cuanto a la procedencia de la clientela del curanderismo y la cultura portada, la mayoría pertenece a la colectividad boliviana y peruana, luego del noroeste argentino (NOA), y por último de la ciudad de Buenos Aires.

La mayoría de la población de los sectores populares que concurre a la Pequeña Bolivia o los individuos de la cultura andina hibridada (entre lo originario y español) unen más que separan los campos de la salud y de la religión, en el tránsito por los circuitos etnomédico y religioso.

Las representaciones sociales de la comunidad andina sobre la concepción de la salud-enfermedad-tratamiento tienen una connotación holística de la persona respecto a la integración física/mental/espiritual, hallando en el curandero, el especialista para la atención y el tratamiento de las enfermedades. Por tanto el ser humano tiene que mantener un equilibrio en los aspectos físico, natural, social y sobrenatural. 
Este contexto se trata de una identificación cultural de los consultantes con los especialistas, quienes les brindan un marco de comprensión de las causas de los malestares y padeceres y las posibles soluciones, mediatizadas a través de prácticas rituales diversas, incluyendo conocimientos provenientes de la New Age (en el caso del curandero que incorpora la metafísica y el counselling).

De esta manera, los curanderos se presentan ante el público andino con elementos culturales claramente comprensibles e integradores, y ante una nueva clientela proveniente de sectores de clase media urbana, como un curandero exótico, que aporta una variante diferente y atractiva en el mercado de bienes simbólicos de sanación.

\section{Bibliografía}

Absi, P. (2005). Los ministros del diablo: el trabajo y sus representaciones en las minas de Potosí. La Paz, Bolivia: IRD-Embajada de Francia en Bolivia-IFEA-Fundación PIEB. https://doi.org/10.4000/books.ifea.4003

Anderson, N. (1980). Sociología de la comunidad urbana. México: Fondo de Cultura Económica.

Berger, P. (2006). El dosel sagrado: para una teoría sociológica de la religión. Barcelona: Kairós.

Bianchetti, M.C. (2012). Métodos de diagnóstico vigentes en los curanderos andinos del noreste argentino En Revista Pueblo Continente. Vol 23. №1, Enero-junio 2012. Universidad privada Antenor Orrego: Trujillo, Perú. (pp. 57-71).

Bianchetti, M.C. (2014). Curanderos, especializaciones y afecciones que rigen aún hoy en el área andina centro oeste suramericano. Scripta Ethnologica, vol. XXXVI, (pp. 129-165).

Bourdieu, P. (1989). Espacio social y poder simbólico y la disolución de lo religioso. En Cosas dichas. Madrid: Gedisa.

Bourdieu, P. (2010). La eficacia simbólica. Buenos Aires: Biblos.

Briones Gómez, R. (1996). La persistencia del curanderismo entre las ofertas de Occidente. En Gómez García, Pedro (ed.).El curanderismo entre nosotros (pp. 74-129), Universidad de Granada.

Brun, H. Z. (2009). Un acercamiento a la visión cósmica del mundo andino. Disponible en www.scielo.org.bo

Durkheim, É. (1912).Las formas elementales de la vida religiosa, Buenos Aires: Shapire, 1968.

Fernández Juárez, G. (1998). Los Calallawallas: medicina indígena en los Andes bolivianos, Universidad de Castilla-La Mancha.

Fernández Juárez, G. (2004).Yatiris y ch'amakanis del altiplano aymara: sueños, testimonios y prácticas ceremoniales.Quito: Abya-Yala.

Forni, F. Mallimaci, F. y Cárdenas, L. A. (2004). Guía de la diversidad religiosa, tomo I. Buenos Aires: Biblos.

Forni, F. Mallimaci, F. y Cárdenas, L. A. (2007). Guía de la diversidad religiosa, tomo II. Buenos Aires: Biblos. 
Foster, G. (1994). Hipócrates Latin American Legacy: Humoral medicine in the New World. Nueva York: Gordon \& Breach Science Publisher.

Good, Ch. (1987). Ethnomedical systems in Africa. Nueva York: The Guildorf Press.

Guevara Corral, R. D. (1988). El curandero urbano. Colombia, Ciencia y Tecnología, vol. 6, No 44 (pp. 203-221).

Goldberg, A. (2009). Salud e interculturalidad. Aportes de antropología médica para el abordaje sociosanitario de la población boliviana en la ciudad de Buenos Aires. En Buenos Aires Boliviana. Migración, construcciones identitarias y memoria. Temas de Patrimonio Cultural 24. Ministerio de Cultura de Buenos Aires. Gobierno de la Ciudad.

Huanca, T. (1990). El yatiri en la comunidad aymara. La Paz: HISBOL.

Idoyaga Molina, A. (1999-2000).La medicina humoral, las nociones de cálido y frío y las prácticas terapéuticas tradicionales en la Argentina. Folklore Latinoamericano, tomo III.

Idoyaga Molina, A. (2002). Culturas, enfermedades y medicinas, reflexiones sobre la atención de la salud en contextos interculturales de Argentina.Buenos Aires: CAEA-Conicet.

Kleimann, A. (1980). Patients and Healers in the Context of Culture. Berkeley: University of California Press.

Lévi-Strauss, C. (1958). Antropología estructural. Buenos Aires: Paidós.

Mamani, L.D.O. (2013).Medicina tradicional aimara, Lima. Disponible en http://dialnet. unirioja.es

Menéndez, E. (2002). La parte negada de la cultura: relativismo, diferencias y racismo. Barcelona: Bellaterra.

Nebreda, J. (1997). Sobre hechiceros y curanderos o el antropólogo y su estrategia. En Gómez García, Pedro (ed.). El curanderismo entre nosotros (pp. 131-147). Universidad de Granada.

Polia Meconi, M. (1996). Despierta remedio despierta: adivinos y médicos del Ande. Lima: Fondo Editorial de la Pontificia Universidad Católica.

Solé, C., Parella, S. y Cavalcanti, L. (2008). Aplicación de los campos sociales transnacionales en los estudios sobre migraciones. En Solé, Carlota, Daedalus (pp.163194). Nueva Jersey.

Tomoeda, H. (1992). Curanderos urbanos: salud y ritual en el Cuzco contemporáneo, Senri Ethnological Studies, № 33 (pp.183-189).

Weber, M. (1912). La ética protestante y el espíritu del capitalismo. México: FCE, 1964.

\section{Organismos internacionales}

OMS. (2002) Estrategias de la OMS sobre la medicina tradicional.(2002-2005) Ginebra: OMS.

OMS (2013) Estrategias de la OMS sobre la medicina tradicional. Ginebra OMS.

\section{Organismos nacionales}

Comuna 9, área de Participación Ciudadana, Ciudad Autónoma de Buenos Aires, Gobierno de la Ciudad Autónoma de Buenos Aires. 


\section{Legislación}

Código Penal Argentino: Las acciones del curanderismo se hallan enmarcadas dentro del ejercicio ilegal de la medicina: Libro II, Título VII: Delitos contra la Seguridad Pública. Capítulo IV: Delitos contra la Salud Pública”. El artículo 208 tipifica al curanderismo.

\section{Publicaciones digitales}

Yatiris. 15 de diciembre de 2013. Disponible en www.opinion.com.bo/informe-especial/2013

(C) 2020 por el autor. Licencia a ANDULI, Editorial Universidad de Sevilla. Este artículo es un artículo publicado en acceso abierto bajo los términos y condiciones de la licencia Creative Commons Attribution (CC BY) (https://creativecommons.org/ licenses/by-nc-sa/4.0/). 
